\title{
João Ternura: romance de uma vida
}

Marcos Vinícius Teixeira

Resumo

\begin{abstract}
Estudo do romance João Ternura, de Aníbal Machado, a partir da relação, já indicada pela fortuna crítica, entre a obra e a vida do escritor, observando tanto a presença de elementos autobiográficos quanto os processos de ficcionalização a que esses dados são submetidos.
\end{abstract}

Palavras-chave: Aníbal Machado. João Ternura. Vida e obra.

Quem abre o livro João Ternura se depara, logo na introdução, com a seguinte frase de Aníbal Machado: "É possível que alguns leitores, de tanto ouvirem falar neste livro, o recebam de pedras na mão" (MACHADO, 1978, p. 3). O escritor se dirige aos leitores que, de alguma forma, acompanharam a gestação de seu personagem e que aguardaram, por várias décadas, a publicação de seu romance. É que, tendo divulgado algumas partes de sua obra, deu vida a um personagem que ainda não podia ser encontrado nas estantes, ou, como diz Aníbal, não habitava um livro. Criou-se assim um mito acerca de João Ternura e um certo incômodo na crítica literária que o aguardava e via no personagem uma espécie de "parente" de Macunaíma ou de João Miramar.

Frustraram-se os críticos, pois João Ternura só foi publicado em 1965, um ano após a morte do autor. Nasceu velho ou, como observariam alguns críticos, chegou atrasado em algumas décadas. Tratando-se de livro que não foi apenas interrompido, mas que sofreu diversas elaborações nas décadas antecedentes à sua publicação, não pôde ser considerado como obra da primeira fase modernista.

Parece assim que o principal motivo para o engavetamento de João Ternura pode ter sido justamente a forte tendência de seu romance ser lido como obra da fase heróica do movimento modernista. Essa hipótese se torna mais sustentável quando recordamos que Aníbal Machado interrompeu seu livro em 1932, época em que, segundo Renard Perez, Oswald de Andrade declarou que João Ternura era "um dos pontos mais altos do romance nacional" (PEREZ, 1960, p. 24).

Por outro lado, sabe-se hoje que, ao escrever João Ternura, Aníbal buscou elementos em sua própria vida para a constituição de seu personagem. Evidentemente, esses dados biográficos, que encontramos ao longo do romance, aparecem transformados, ficcionalizados. Essa relação entre vida e obra já havia sido apontada pela fortuna crítica e norteou o presente estudo. 
Percebe-se com isso que se trata de uma obra de intimidade. O escritor chega a considerá-la, na introdução, como uma forma que tinha para restabelecer o "gosto e o interesse de viver" (MACHADO, 1978, p. 3). Este forte envolvimento com seu romance ou esta presença de elementos biográficos no mesmo é outra condição a ser considerada para a demora de sua publicação. Publicar João Ternura no momento em que todos o esperavam seria, então, ao mesmo tempo, permitir a leitura de seu livro em comparação com os romances da primeira fase modernista e se expor ao público, dado que a relação entre vida e obra também seria inevitável. O próprio Aníbal Machado declarou certa vez, ao tratar de seu romance, que o livro carregaria a alma do escritor: "Um livro! Mercadoria à venda em toda parte com a alma da gente nua, exposta, cega e surda, mas nua..." ${ }^{1}$

Levando em consideração a estreita relação existente entre a vida e a obra do escritor, estudei o romance de Aníbal Machado tentando mostrar como os dados biográficos foram ficcionalizados e, transformados, ajudam a compor a história de João Ternura da Silva. Recorri, para isso, não só aos textos autobiográficos, mas busquei nos diversos textos do autor informações sobre a sua vida. Tratando-se de escritor que deixou poucos textos dessa natureza, busquei também na crítica literária depoimentos que ajudassem a esclarecer a relação pesquisada no romance.

Surpreendi-me então com a declaração de Pedro Nava, feita em Beira-mar, de que João Ternura já estava sendo escrito em 1922 e talvez tivesse sido iniciado quando o autor residia em Aiuruoca, sul de Minas Gerais, ou seja, em 1919. A informação se completa com o fato de o memorialista ter ouvido do próprio Aníbal a leitura de trechos de seu romance quando este residia na rua Tupis, em Belo Horizonte, no ano de 1922. Como se sabe, Aníbal Machado se mudaria para o Rio de Janeiro em 1923. A declaração de Nava se torna importante uma vez que praticamente todos os textos críticos marcaram em 1926 o ano em que o escritor teria iniciado João Ternura.

Aníbal Machado nunca informou realmente quando teria iniciado o seu romance. $\mathrm{Na}$ introdução que escreveu para o livro ele afirma que não se lembra quando o iniciou e que também não sabia dizer quantas vezes o esqueceu durante a escrita. É possível que Aníbal Machado não desejasse que os críticos soubessem quando realmente começou a escrever o livro, pois, além de representar um maior tempo de gestação da obra, revelaria uma proximidade temporal com o marco modernista que foi a Semana de 22. Pode-se dizer, graças ao depoimento de Nava, que a obra demorou mais de quatro décadas para ser escrita.

Como observa Fernando Py, o romance João Ternura pode ser dividido em três partes. Deste modo, tem-se: a infância do personagem, na primeira parte; a mudança do personagem para o Rio de Janeiro e sua vida de vagabundo nesta cidade, na segunda; e, na terceira, o carnaval e a "dupla morte" do personagem.

A primeira parte do romance é a que apresenta maior aproveitamento de dados biográficos. Embora constituída por fragmentos, a história da infância de João Ternura pode ser lida numa linha de progressão. O livro I reconstitui o nascimento e a primeira infância do personagem, terminando com a entrada no colégio do Rio de Janeiro. No livro II é narrado o retorno de João Ternura à chácara, seu ingresso num colégio de padres da região, de onde fugirá e retornará para a chácara.

O espaço é significativo. A chácara onde Ternura passa a sua infância é cortada por um rio e de lá se avista os trilhos da locomotiva. Assim como o rio, a chácara não tem nome e a única referência acerca da estrada de ferro é a sigla EFCB. Consultando os breves textos autobiográficos somos informados de que Aníbal Machado nasceu 
numa chácara, ${ }^{2}$ localizada perto da cidade de Sabará, que é cortada pelo Rio das Velhas e pelos trilhos da Central do Brasil.

Não se trata, entretanto, de buscar na obra a vida do escritor, mas de mostrar como esses dados autobiográficos aparecem transfigurados e transformados em ficção. Uma boa forma de exemplificar como a vida de Aníbal aparece transformada na obra seria relembrar um episódio do romance em que o personagem foge de uma escola de padres.

No texto intitulado "Autobiografia", Aníbal Machado nos informa que, quando menino, passou um período difícil durante a época em que estudou no Colégio Dom Viçoso: "Rezávamos alto e sem fé naquele seminário leigo" (MACHADO, 1994a, p. 290291). O escritor afirma ainda que tinha uma vontade secreta de incendiar o colégio. No entanto, prevalece a apatia e a aceitação do mundo. Já em seu romance, João Ternura se revolta contra o casarão onde os padres ensinavam latim e foge pelo rio: "Era a revolta contra as trevas, o mofo, a angústia" (p. 61).

A fuga de João Ternura pelo rio representa também uma busca pela própria liberdade. Essa busca se torna constante na segunda parte da obra: o personagem vive agora no Rio de Janeiro, habita um quarto de pensão e, diferentemente do escritor, não possui família, vivendo solitariamente. Distante da chácara paterna, João Ternura se torna um desajustado, um joão-ninguém, um personagem que, tornado homem, não chega a seu amadurecimento, ou melhor, recusa-se a se comportar como os demais, vivendo segundo as regras que estabelece. Marcado pela ingenuidade e lirismo, revela-se preocupado com a natureza humana e se compromete com a alegria de viver. O personagem, portanto, representa valores próprios, que entram em conflito com aqueles socialmente estabelecidos.

Assim, embora a segunda parte do romance apresente menor aproveitamento de dados biográficos (tal como acontece com a terceira), eles não deixam de se fazer presentes na narrativa: o personagem e os episódios, ao se afastarem cada vez mais das referências biográficas diretas, acabam por compor um modo de ver o mundo que o reaproxima do autor. É o que pode ser percebido no que talvez seja o único episódio de fundamento claramente biográfico desta parte do romance. Trata-se do episódio "A lei contra a lei do amor", que guarda nítida relação com a época em que Aníbal Machado trabalhou como delegado de polícia. Curiosamente, trata-se de uma época cuidadosamente evitada pelo autor em seus textos autobiográficos.

Esse modo de ver o mundo unido à imagem de um personagem vagabundo permite que este seja relacionado a Carlitos, de Charles Chaplin. O próprio Aníbal assume, em 1929, a influência que recebeu de Chaplin: "Carlitos influiu. Tanto assim que eu me vejo obrigado a escrever um ensaio sobre Carlitos assim que publicar João Ternura" (MACHADO, 1994b, p. 50). De fato, ainda que não publicando o romance, o escritor chegaria a escrever três ensaios sobre o tema, que possuem importância para a abordagem em questão.

A terceira parte, como foi dito, pode ser dividida em duas. Tem-se assim a parte do Carnaval e a da "dupla morte". O episódio do Carnaval pode ser relacionado ao surrealismo de André Breton. Os críticos já haviam falado de surrealismo quanto à primeira parte do romance, mas me parece ser justamente a parte do Carnaval que melhor corresponderia a uma experiência surrealista feita pelo escritor em sua ficção.

Como se sabe, Aníbal Machado era adepto das idéias surrealistas. Sobre isso declara o escritor: "O mal dos poetas foi ter consentido no distanciamento entre o sonho e a realidade. A meu ver, só os surrealistas e seus precursores lutaram contra essa ruptura" (MACHADO, 1994b, p. 60). Para o autor, o Brasil constituiria um campo 
propício para o movimento: "Basta o Carnaval para atestar quanto o nosso povo está próximo das forças inconscientes que precisa desencadear" (Machado, 1994b, p. 6162).

Nesse sentido, o tema do Carnaval permite ao autor realizar o que se pode chamar de uma experiência surrealista, podendo causar certo estranhamento no leitor. É a parte do romance, afinal, que mais explora situações absurdas, que fogem às regras da verossimilhança realista. Seria válido lembrar, nesse sentido, o surgimento de Deus durante a festança e a chuva de pastéis em Vila Isabel.

O romance caminha então para a "dupla morte". Com a primeira morte, o personagem fará uma visita à eternidade, onde será vaiado por criaturas desocupadas e constatará que o paraíso não existe: "Circunvagou o olhar aflito, à procura das portas do paraíso. Desde pequeno ouvira falar nelas. E não havia nada" (p. 206). Ternura consegue então voltar e ter o direito de viver mais algum tempo na Terra.

De volta, o personagem sofre uma profunda transformação. Permitirá, então, que os acontecimentos da vida lhe aborreçam, dirá que está envelhecendo, que as mulheres não mais o quererão, que tem sentido solidão. A segunda morte, ou desaparecimento, é desejada pelo próprio personagem. Assim, Ternura permanece atrás da Serra do Mar, observando a evolução do Rio de Janeiro. Aos poucos o personagem vai sendo esquecido por todos e, não reconhecendo mais a cidade em que viveu, desaparecerá definitivamente.

Uma pedra é utilizada para marcar o esquecimento de Ternura no romance. Retirada do rio da infância, essa pedra metaforiza o coração e a vida do personagem. Assim, o instante em que ocorre o seu desaparecimento definitivo corresponde, na obra, ao momento em que a pedra é jogada fora, voltando à terra.

É preciso considerar, ainda, que a pedra pode constituir uma referência feita pelo escritor à sua terra natal. Nesse sentido, é válido observar o nome da cidade em que nasceu: Sabará. Em Passeio a Sabará, Lúcia Machado de Almeida explica que o termo que dá nome à cidade significa pedra reluzente, cristal. Essa relação reforça a idéia de um livro-testamento, já apontada anteriormente por Valdemar Cavalcanti.

Assim sendo, a relação entre vida e obra está presente, em maior ou em menor grau, em todo o romance. É curioso observar, nesse sentido, que Aníbal Machado escreveu, ainda que de forma breve, sobre o assunto. Os apontamentos que o autor faz em seu texto podem ser direcionados à sua própria obra:

As memórias valem às vezes pela pintura indireta dos costumes sociais e das reações do comportamento humano em determinado meio. Valem também quando o dado biográfico se dissolve em poesia. Aqui, já não é mais memória, é superação do real pela evocação lírica ou pelo humor. O que fizemos passa a ser contado como aquilo que desejávamos fazer; o que nos aconteceu, como o que sonhávamos acontecesse. (Machado, 1994a, p. 12).

\footnotetext{
Notas

$\prod_{1}$

${ }_{1}^{1}$ Retiramos essa frase de Aníbal Machado de uma citação recuada presente na introdução do livro Parque de diversões. Esse texto de Aníbal, segundo o autor da introdução e organizador da edição, Raúl Antelo, pertence a um posfácio inédito de João Ternura. No entanto esse mesmo posfácio não foi reproduzido no livro em questão - que reúne inéditos e esparsos - e só tivemos acesso ao trecho citado pelo crítico em seu texto.

${ }^{2} \mathrm{Na}$ coleção Aníbal Machado do Acervo de Escritores Mineiros da UFMG encontra-se um quadro, pintado por Francisco Rocha, em que a chácara é retratada. O título do quadro, Chácara do fogo apagou, indica o nome do lugar em que o escritor passou sua infância.
} 
Abstract

This is a study of João Ternura, a novel by Aníbal Machado, from the relation, already indicated by his critics, between the work and life of the writer, observing the presence of autobiographic elements as well as the fictionalization processes of which these data are submitted.

Key words: Aníbal Machado. João Ternura. Life and work.

\section{Referências}

ALMEIDA, Lúcia Machado de. Passeio a Sabará. 3.ed. [ilustrações de Guignard]. São Paulo: Martins, 1964.

BRETON, André. Manifestos do surrealismo. São Paulo:

Brasiliense, 1985.

CAVALCANTI, Valdemar. "Vida e morte de João Ternura". Suplemento literário do Minas Gerais. Belo Horizonte: S. Literário, ano X, n. 477, nov. 1975, p. 04.

CONY, Carlos Heitor. Charles Chaplin. Rio de Janeiro: Civilização Brasileira, 1967.

MACHADO, Aníbal. A arte de viver e outras artes: Cadernos de João, ensaios, crítica dispersa e auto-retratos. Rio de Janeiro: Graphia, 1994a.

MACHADO, Aníbal. João Ternura. 4. ed. Rio de Janeiro: J. Olympio, 1978.

MACHADO, Aníbal. Parque de diversões. Belo Horizonte: UFMG; Florianópolis: UFSC, Coleção inéditos e esparsos. 1994b.

NAVA, Pedro. Beira-mar. 5. ed. São Paulo: Ateliê Editorial, 2003.

PEREZ, Renard. Escritores Brasileiros Contemporâneos. Rio de Janeiro: C. Brasileira, 1960.

PY, Fernando. "João Ternura”. Chão de crítica. Rio de Janeiro: F. Alves; Brasília: INL, 1984, p. 235-238.

ROCHA, Francisco. Chácara do fogo apagou. 1927, óleo sobre tela. Coleção Aníbal Machado - Acervo de Escritores Mineiros da UFMG. 